\title{
Modeling Peculiarities of Reinforced Crack of Hydraulic Fracture of Coal Seams for Estimation of Their Permeability

\author{
BAEV MIHAIL ALEKSEEVICH
}

\section{Mining institute, t.f. Gorbachev Kuzbass State Technical University, 650000, Kemerovo, Russia}

\begin{abstract}
The main differences of coal bed methane from other unconventional hydrocarbon resources are shown. Characteristics features of hydraulic fracture operation of coal seams are analyzed. The factors, affecting the permeability of reinforced crack of hydraulic fracture are marked. And the modeling peculiarities of reinforced crack of hydraulic fracture of coal seams are analyzed.
\end{abstract}

Keywords: coal bed methane, hydraulic fracturing, proppant, permeability, contact strength.

\section{Introduction}

The modern world economy is characterized by high energy resources consumption. The development of fuel and energy and metallurgical complex, petrochemical and chemical industry is based on the extensive use of various kinds of mineral resources extracted from the earth. Fuel, energy and technological raw materials oil, natural gas and coal are widely used. The humanity growing needs in these minerals make people increase their extraction continually. Gradual exhaustion or substantial reduction of these reserves in easily accessible deposits has led to complexity and high cost of their production. In this regard, one of the priority tasks is the development of unconventional hydrocarbon resources, which include: heavy oils, oil (tar) sands, coal bed methane, shale gas and oil, gases of tough rocks, gas hydrates and water dissolved gases. Coal bed methane (CBM) has a number of differences from other unconventional resources. Firstly, the high level of its extraction technology allows considering the CBM production possible on a commercial scale and economically useful. This is confirmed by successful projects of coal bed methane reserves development in such countries as USA, Canada, Australia, etc. Secondly, coal bed methane is a high quality and environmentally friendly energy and chemical raw material. Methane concentration in natural gas mixture of coal seams is $80-98 \%$, and the impurities content is minimized. Therefore, there is no need in deep cleaning - in most cases it is sufficient just to dry it. Thirdly, large-scale field methane production as an independent mineral resource will not only meet needs of the coal-mining regions in gas, but also will reduce gas hazard of coal mining in future mines. This, in turn, is one of the conditions for significant increase in coal production.

\section{Characteristic of the work}

Early methane extraction by wells from the surface (before mining) is done by using the special technology of coal seams gas recovery intensification. In the world practice various methods have been used, such as: seam hydraulic fracturing (SHF), caving, horizontal directional 
drilling (HDD), pneumo- and hydrodynamic drag (MPE, PHDD and HDT), reactant treatment of wells, the wave action to a seam, helium, nitrogen and carbon dioxide injection into coal seams, plasma impulse excitation (PIE), foam-nitrogen hydraulic fracturing and others. The hydraulic fracturing method is widely used for CBM production. During the hydraulic fracturing process a special technological liquid is pumped under high pressure and high rate into the seam. At one stage of hydraulic fracturing a propping agent (proppant) in the form of natural sand or ceramic granules of a certain size and concentration is added into fracturing liquid. Proppant is distributed in the cracks to prevent their closing after the operation closure. The main purpose of hydraulic fracturing is to create a system of deep penetration into the seam cracks, which links a well with a network of natural origin cracks and increases the drainage area. Such high permeability cracks are pathways and facilitate the flow of gas from the seam depth to the well in order to achieve economically sound production rates. Thus, the wells productivity is associated with cracks geometry and their residual permeability.

One of the main factors in hydraulic fracturing is display of strength and deformation properties of rocks. The difference of coal physical and mechanical properties from other reservoir formations and bedding conditions determines the peculiarities of hydraulic fracturing technology of coal seams and this exposure method effectiveness. The value of Young's modulus has great influence on geometry of cracks, resulting from hydraulic fracturing ${ }^{[1,2]}$. The cracks tend to grow in length and height in rocks with high Young's modulus, being relatively small in width (crack opening). In rocks with low Young's modulus, such as coal, cracks should be relatively wide and short. However, the developed system of natural cracks in coal seams can contribute to high filtration of fracturing liquid deep into the formation; this prevents the cracks growth in width.

Another important factor in cracks formation of fracture is a type of fracture liquid. The technology «slickwater» became widespread for coal seam gas recovery intensification - hydraulic fracturing, using water with a small amount of additives (friction reducers) as a fracturing liquid. As a result of this technology implementation the developed system of cracks is formed; micro seismic studies prove it ${ }^{[2,3,4]}$. Complex geometry of cracks and relatively low disclosure leads to difficulties of their effective proppant attachment. Besides, water has very low sand holding ability, which also reduces the quality of cracks attachment.

Numerous studies show that the main factors affecting the permeability of cracks of hydraulic fracture and proppant packing are: closure pressure of reinforced cracks, temperature, mechanical properties of rocks, proppant type, grain size and surface concentration of proppant, distribution of proppant in a crack, gel remnants, proppant destruction, particle migration, proppant indentation in cracks walls. The influence of all these factors is studied well. However, the research of filtration properties of reinforced cracks of hydraulic fracture of coal seams has a number of features.

Permeability of reinforced cracks of fracture in a coal seam differs from the permeability, determined in accordance with a standard method of measuring the duration of proppants conduction, described in the standards ISO 13503-5 and API RP $19 \mathrm{D}^{[5]}$. The standard method does not fully take into account the peculiarities of physical and mechanical properties of coal and the conditions of coal seams bedding, but information 
concerning the study of their impact on the filtration ability of reinforced cracks of hydraulic fracture of coal seams is not enough.

In this regard the urgent problem is the task of further investigation of the process of cracks attachment of hydraulic fracture and experiments conduction to measure the permeability of proppant packing in conditions close to the seam conditions. In our case it is necessary to consider the impact of the unique properties of coal seams, which are unconventional reservoirs of methane. What properties of coal should be considered when comparing coal with other rock-reservoirs in the aspect of the analyzed problem? Firstly, these are those properties, which can affect the permeability of proppant bands. These include mechanical properties and parameters which characterize them. In the research ${ }^{[6]}$ we provide objectives that, in aspect of the analyzed problem, the exponent, giving a generalized assessment of rock properties for the process of cracks attachment of hydraulic fracture by granular material, is contact strength of a rock. Furthermore, in accordance with the method described in ${ }^{[7]}$, we performed some experiments on coal samples and determined the index value of the contact strength (63.6 mPas). According to this parameter coal significantly differs from sandstone, laboratory samples of which are used in a standard test for measuring the duration of proppants conductivity. Under certain conditions, this difference may have decisive influence on the residual permeability of reinforced cracks of hydraulic fracture. For experimental verification of this impact some studies should be done to investigate filtration properties of reinforced cracks of hydraulic fracture of a coal seam; thus instead of standard laboratory sandstone samples it is encouraged to use the samples, made of coal equivalent material, as to make samples directly from coal, with certain requirements (size, shape) is technically difficult.

From this, it was proposed to produce samples by filling the cement slurry of definite composition in a special mould. This approach is due to several reasons. Firstly, the samples are very convenient to make. The special mould, designed for preparation of standard samples from sandstone, can be used as a mould for filling. After set of mortar and maturing the resulting sample has the required size and shape. Secondly, adjusting accordingly the cement slurry properties (change in its water-cement ratio, input of various additives), it is possible to obtain the necessary cement stone with certain parameters. Thirdly, this material is very affordable and inexpensive.

Let's analyze in detail the manufacture of cement mortar samples. In order to find the desired composition of the solution let's proceed from the following considerations. Since contact strength is associated with compressive resistance ${ }^{[7]}$, it is possible to determine what strength cement stone should have to satisfy the requirement in terms of contact strength.

It is easy to see that its compressive resistance should be close to the strength of coal (8-20 mPas for coals of Kuznetsk Basin $\left.^{[8]}\right)$. From literature ${ }^{[9]}$ we know that connection of strength of cement stone with water cement ratio of the solution, from which it is made and with cement activity, is known (e.g., water-cement ratio law). Thus, water-cement ratio $\mathrm{W} / \mathrm{C}$ $=0.65$ corresponds to compressive resistance of cement stone, prepared from a solution based on Portland cement M400 equal to $20 \mathrm{mPas}$. Consequently, the cement mortar with such water cement ratio will be basic in our further investigations.

In order to confirm the experimental data of theoretical reasoning in accordance with the method described in ${ }^{[7]}$, some 
experiments were performed to determine contact strength of cement stone. In experiments cement mortars with water cement ratio $\mathrm{W} / \mathrm{C}=0.65$ were prepared based on Portland cement PC400 GOST 31108-2003 by Topkinsky cement plant. Test solutions were prepared with tap drinking water. Samples-cubes, size $70 \times 70 \times 70 \mathrm{~mm}$, were filled from solutions, as well as samples of cylindrical shape with diameter of $55 \mathrm{~mm}$ and $60 \mathrm{~mm}$ high. After twenty-four hours samples were taken from the mould, and the remaining time were stored in a room temperature $(20 \pm 3)^{\circ} \mathrm{C}$ and with relative humidity of $(65 \pm 10) \%$. Samples of the age of 28 days were tested on contact strength. The results of laboratory tests are shown in Table 1.

Table 1: The results of measurements and calculations of cement stone contact strength

\begin{tabular}{|c|c|c|c|c|}
\hline $\begin{array}{c}\text { № } \\
\mathrm{p} / \mathrm{p}\end{array}$ & $\begin{array}{c}\text { Indentor's base } \\
\text { area }\left(\mathrm{m}^{2}\right)\end{array}$ & $\begin{array}{c}\text { The average failure } \\
\text { load(H) }\end{array}$ & Tests number & $\begin{array}{c}\text { Contact strength, } \\
(\mathrm{mPas})\end{array}$ \\
\hline 1 & $7.07 \cdot 10^{-6}$ & 833.9 & 22 & 52.6 \\
\hline 2 & $14.52 \cdot 10^{-6}$ & 1226.3 & 20 & \multirow{2}{*}{5} \\
\hline
\end{tabular}
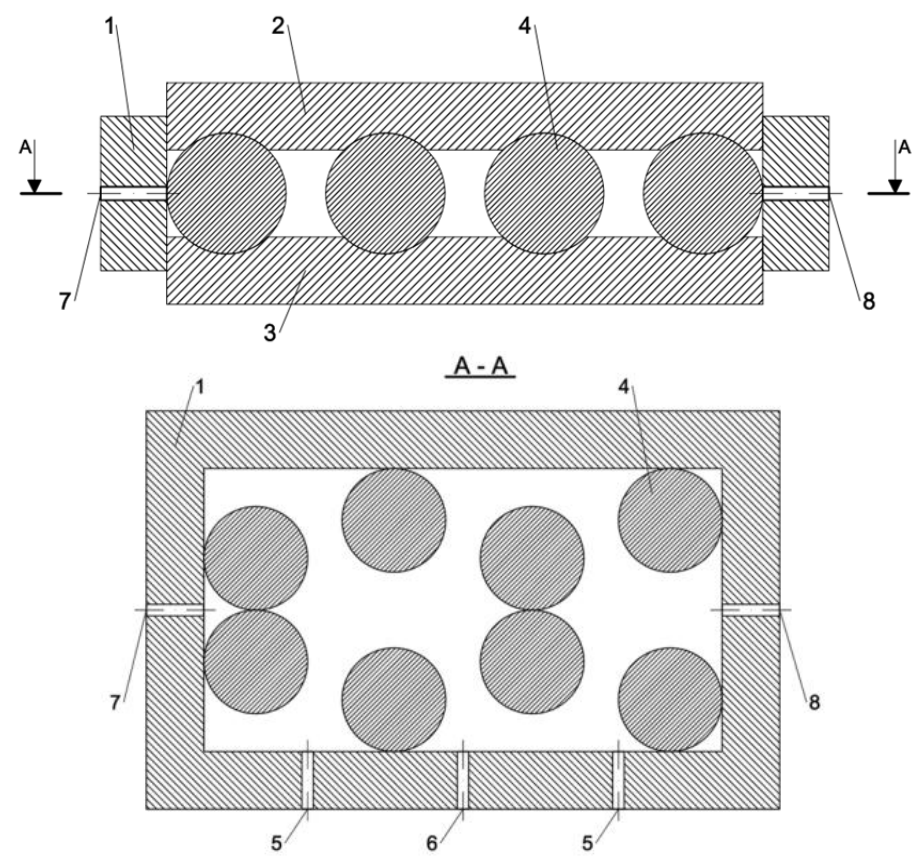

Fig. 1: The model diagram of a reinforced crack of hydraulic fracture of coal seams:

1 - carcass; 2 and 3 - the top and bottom sample of the equivalent material; 4 - proppant grains; 5 holes for pressure gauges connecting; 6 - a hole for the temperature sensor connecting; 7 - a hole of fluid input; 8 - a hole of fluid output.

The data obtained in the experiments are in good agreement with the reference values of contact strength of cement stone and are close to the values of certain indicators of contact strength of coal. Due to satisfactory results of laboratory tests it was decided to produce samples from the cement mortar for measurements of permeability of reinforced cracks of hydraulic fracture.

In addition to these in the abovementioned standards it is provided to 
carry out some measurements with constant surface concentration of proppant. It is necessary to consider the impact of the magnitude of the surface concentration of proppant in modeling of reinforced cracks of hydraulic fracture of coal seams. This will bring the modeling

\section{Conclusion}

Overall, the results of the researches showed the feasibility and desirability of further study of a reinforced crack of hydraulic fracture conductivity using samples made of an equivalent material. To produce samples it is proposed to fill the cement slurry composition in a certain special mould.

Before making samples for conductivity measurements the control measurement should be done to test contact strength of cement stone on samples specially prepared for this. It will clarify the formulation of an applied mortar. Besides, while modeling of reinforced cracks of hydraulic fracture of coal seams the impact of the magnitude of the surface concentration of proppant must be considered.

\section{References}

[1] Economides, M.J. Modern Fracturing: Enhancing Natural Gas Production / M.J. Economides, T. Martin. - Energy Tribune Publishing, 2007 - 509 p.

[2] Coal Bed Methane: Principles and Practices / R.E. Rogers, K. Ramurthy, G. Rodvelt, M. Mullen. - Halliburton Co., 2007. - 504 p.

[3] Integrating Fracture Mapping Technologies to Optimize Stimulations in the Barnett Shale / M.K. Fisher, C.A. Wright, B.M. Davidson, A.K. Goodwin, E.O. Fielder, W.S. Buckler, N.P. Steinsberger // Paper SPE 77441. - 2002. conditions to the real seam conditions. In accordance with the foregoing a diagram of a model of a reinforced crack of hydraulic fracture of coal seams is given on Fig. 1 (assuming the formation of proppant packing in a crack as a partial monolayer).

[4] Palisch, T.T. Slickwater Fracturing: Food for Thought / T.T. Palisch, M. Vincent, P.J. Handren // Paper SPE 115766. - 2010.

[5] API RP 19D. Recommended Practice for Measuring the Long-term Conductivity of Proppants. First Edition (ISO 13503-5:2006, Identical) (Includes July 2008 Errata). - 2008.

[6] Baev, M.A. Some results of investigation of reinforced crack of hydraulic fracture of coal seam stability [electronic resource] / / Proceedings of the VI All-Russia. 59th scientific conference with international participation "Young Russia", 22-25 April. 2014, Kemerovo [electronic resource] / «T.F. Gorbachev Kuzbass State Technical University»; Editorial Board.: V.Y. Blumenstein (Ed.). [and others] - Kemerovo, 2014. - 1 electron disc (CD-R).

[7] Baron, L.I. Contact strength of rocks / L.I. Baron, G.L. Glatman. - Moscow: Nedra, 1966. - 227 p.

[8] Physical and technical properties of rocks and coals of Kuznetsk Basin: reference guide / G.G. Shtumpf, Y.A. Ryizhkov, V.A. Shalamanov, A.I. Petrov. - Moscow: Nedra, 1994. - 447 p.

[9] Dvorkin, L.N. Basics of concrete science / L.N. Dvorkin, O.L. Dvorkin. St. Petersburg: LLC «Stroi-Beton», 2006. $-692 \mathrm{p}$. 